\title{
Hydrogen Sulfide Inhibits Abnormal Proliferation of Lymphocytes via AKT/ GSK3 $\beta$ Signal Pathway in Systemic Lupus Erythematosus Patients
}

\author{
Yanfang Han ${ }^{a}$ Fanqin Zeng ${ }^{a}$ Guozhen Tan ${ }^{a}$ Chuntao Yang ${ }^{b}$ Hongfeng Tang ${ }^{c}$ Yijin Luo \\ Jianqiang Feng ${ }^{d}$ Hui Xiong ${ }^{a}$ Qing Guo ${ }^{a}$ \\ aDepartment of Dermatology, Sun Yat-sen Memorial Hospital, Sun Yat-sen University; Guangzhou; \\ ${ }^{b}$ Department of Physiology, Guangzhou medicial University, Guangzhou; ' Department of Dermatology, \\ The first people's hospital of Shunde, Foshan; 'Department of Physiology, Zhongshan School of \\ Medicine, Sun Yat-sen University, Guangzhou
}

\section{Key Words}

AKT • GSK3 $•$ Cell cycle • Hydrogen sulfide • Lymphocytes • Systemic lupus erythematosus

\begin{abstract}
Background/Aim: The abnormal activation of the AKT/GSK3 $\beta$ signal pathway in lymphocytes from systemic lupus erythematosus (SLE) patients plays an important role in the pathogenesis of the disease. Recently Hydrogen sulfide $\left(\mathrm{H}_{2} \mathrm{~S}\right)$ has been recognized as a crucial gaseous signaling molecule, involved in regulation of cell proliferation. However, the role of $\mathrm{H}_{2} \mathrm{~S}$ in regulating the abnormal activation of lymphocytes from SLE patients has not been established. This study was conducted to investigate the effect of $\mathrm{H}_{2} \mathrm{~S}$ on lymphocytes and to explore the mechanisms involved. Methods: The lymphocytes were isolated from SLE patients with or without renal disease and healthy controls. The cells were treated as indicated in each experiment. Cell viability was analyzed by CCK-8. Cell cycle distribution was determined by flow cytometry. Western blot was used to detect the expression of phosphorylated AKT

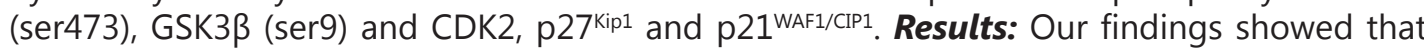
proliferation of lymphocytes was stimulated following treatment with $\mathrm{NaHS}\left(\mathrm{a}_{2} \mathrm{~S}\right.$ donor) at low NaHS concentrations $(<1 \mathrm{mM})$ but inhibited at high NaHS concentrations $(>2 \mathrm{mM})$. Similar results were observed using GYY4137, which is a slow-releasing $\mathrm{H}_{2} \mathrm{~S}$ donor. Pretreatment of lymphocytes from SLE patients with NaHS at high concentrations prior to exposure to phytohemagglutinin (PHA) significantly attenuated proliferation, evidenced by decrease in cell viability and S phase distribution of cell cycle. Pretreatment with NaHS decreased PHA-induced expression of CDK2, phosphorylation levels of AKT (ser473) and GSK3 $\beta$ (ser9) and increased the expression of $\mathrm{p} 27^{\mathrm{Kip} 1}$ and $\mathrm{p} 21^{\mathrm{WAF} 1 / \mathrm{CP} 1}$. Moreover, pretreatment with NaHS blunted the stimulation of SLE lymphocyte proliferation by GSK3 $\beta$ inhibitor lithium chloride. Conclusion: These results demonstrate that $\mathrm{H}_{2} \mathrm{~S}$ inhibits the abnormal activation of lymphocytes from SLE patients through the AKT/GSK3 $\beta$ signal pathway.




\section{Cellular Physiology and Biochemistry}

Cell Physiol Biochem 2013;31:795-804

DOI: 10.1159/000350097

Publisned onine: vilay 31, 2013

C) 2013 S. Karger AG, Basel

www.karger.com/cpb

Han et al.: $\mathrm{H}_{2} \mathrm{~S}$ inhibits Proliferation of Lymphocytes in SLE Patients

\section{Introduction}

Systemic lupus erythematosus (SLE) is an autoimmune disease characterized by various immunological abnormalities. Although the cause of SLE remains incompletely understood, the abnormal activation and proliferation of lymphocytes have been proven important in the pathogenesis of SLE [1].

It has been established that cell proliferation depends on the interactions between cell cycle regulatory proteins, such as cyclin-dependent kinases (CDKs), p27 $27^{\mathrm{Kip} 1}$ and p21 ${ }^{\text {WAF1/CIP1 }}$. Deficient expression of these proteins in T-cells can promote the development of lupus in mice [2]. The PI3K/AKT/GSK3 $\beta$ signal pathway is crucial in regulating autoimmune system [3]. The increased AKT activation plays an important role in lymphoproliferation and results in lymphadenopathy and splenomegaly with accumulation of $\mathrm{CD} 4^{+}$and $\mathrm{CD} 8^{+} \mathrm{T}$-cells, as well as $\mathrm{B}$ cells in such transgenic mice $[4,5]$. We previously found that the proportions of lymphocytes from patients of SLE or SLE with renal disease (RSLE) were reduced in the $G_{0} / G_{1}$ phase and elevated in the $S$ phase after phytohemagglutinin (PHA) treatment. The phosphorylation levels of AKT (ser473) and GSK3 $\beta$ (ser9) were increased while the expressions of p27 $7^{\text {Kip } 1}$ and $\mathrm{p} 21^{\mathrm{WAF} 1 / \mathrm{CIP} 1}$ were decreased in lymphocytes from the patients [6]. It indicates that the AKT/GSK3 $\beta$ signal pathway closely relates to the abnormal activation and proliferation of lymphocytes in SLE patients.

In recent years, $\mathrm{H}_{2} \mathrm{~S}$ has been considered as a biologically relevant signaling molecule with potential roles in several physiological processes, such as, anti-inflammation, promoting cellular signals, protecting vascular endothelium and so on [7-10]. Previous evidence indicates that $\mathrm{H}_{2} \mathrm{~S}$ has biphasic effects on T cell proliferation $[11,12]$, stimulating T cell proliferation at low concentrations while inhibiting at high concentrations. Little work has been focused on the impact of $\mathrm{H}_{2} \mathrm{~S}$ to the proliferation of lymphocytes from SLE patients, and whether the AKT/GSK3 $\beta$ signal pathway was involved in such process. This study aims to clarify the effect of exogenous $\mathrm{H}_{2} \mathrm{~S}$ on the abnormal activation and proliferation of lymphocytes from SLE patients, and explored its potential relation with AKT/GSK3 $\beta$ signal pathway.

\section{Materials and Methods}

\section{Reagents}

Ficoll-Paque density gradient centrifugation medium was bought from Amersham Pharmacia Biotech (Uppsala, Sweden). RPMI 1640 medium and fetal bovine serum were purchased from Gibco (Grand Island, NY, USA). The antibody against cyclin-dependent kinase-2 (CDK2) was from BD Transduction Laboratories (San Diego, CA, USA). Antibodies against p27 ${ }^{\text {Kip1 }}$, p21 ${ }^{\text {WAF1/CIP1 }}$, total AKT, Ser473-phosphorylated AKT, total GSK3 or Ser9-phosphorylated GSK3 $\beta$, and horseradish peroxidase (HRP)-conjugated secondary antibodies were purchased from Cell Signaling Technology (Beverly, MA, USA). RNase A, propidium iodide (PI), monoclonal rabbit anti-GAPDH antibody, phytohemagglutinin (PHA) and GYY4137 were purchased from Sigma-Aldrich Co., (St. Louis, MO). Cell Counter Kit-8 (CCK-8) was purchased from Dojindo Laboratory (Kyushu, Japan). Lithum Chloride ( $\mathrm{LiCl}$ ) was purchased from MP Biomedicals (California, USA). Enhanced chemiluminescence (ECL) detection system was purchased from Applygen Technologies (Beijing, Peoples's Republic of China).

\section{Patients, controls and blood samples}

SLE patients were recruited from the outpatient clinics and inpatient services at the Sun Yat-sen Memorial Hospital, Sun Yat-sen University (Guangzhou, China). The diagnosis of SLE was established based on the 1997 revised American Rheumatism Association criteria. Renal disease was defined as proteinuria of $\geq 0.5 \mathrm{~g} /$ day. The patients were divided in two groups: $10 \mathrm{SLE}$ patients with renal disease (RSLE group) and 9 SLE patients without renal disease (SLE group). All patients were diagnosed with SLE for the first time or without treatment with glucocorticoid or immunosuppressive agent over one month. Ten sex- and age-matched, healthy Chinese volunteers were recruited as controls. Twenty-five milliliters of heparinized venous peripheral blood was collected from each patient and control. The protocol of this study was 


\section{Cellular Physiology and Biochemistry}

Cell Physiol Biochem 2013;31:795-804

\begin{tabular}{l|l}
\hline DOI: $10.1159 / 000350097$ & (C) 2013 S. Karger AG, Basel
\end{tabular}

Han et al.: $\mathrm{H}_{2} \mathrm{~S}$ inhibits Proliferation of Lymphocytes in SLE Patients

approved by the Clinical Research Ethics Committee of Sun Yat-sen University and signed informed consent was obtained from the healthy volunteers and the patients.

\section{Cell culture}

Peripheral blood lymphocytes (PBL) were isolated from heparinized venous blood by Ficoll-Paque density gradient centrifugation. The cells were washed twice with PBS and cultured in RPMI 1640 supplemented with 10\% FBS, 20 mM HEPES (Gibco) and a combination of $100 \mathrm{U} / \mathrm{ml}$ penicillin and 100 $\mu \mathrm{g} / \mathrm{ml}$ streptomycin at $37^{\circ} \mathrm{C}$ in a humidified incubator under an atmosphere of $5 \% \mathrm{CO}_{2}$. After cultured for 4 hours, the suspension cells were collected and used in the following experiments, which were PBL including $\mathrm{T}$ cells and B cells.

Measurement of $\mathrm{H}_{2} \mathrm{~S}$ levels.

$\mathrm{H}_{2} \mathrm{~S}$ levels were measured as previously described [13]. Amperometric $\mathrm{H}_{2} \mathrm{~S}$ sensors (ISO- $\mathrm{H}_{2} \mathrm{~S}-100$, World Precision Instruments, Sarasota, FL, USA) were used for the real-time measurement of dissolved $\mathrm{H}_{2} \mathrm{~S}$ concentration in the medium.

\section{Flow cytometry}

PBL from patients and controls were centrifuged at 1,500 rpm for $5 \mathrm{~min}$. The resulting pellets were washed with $1 \mathrm{ml}$ of ice-cold PBS and fixed with $70 \%$ ethanol at $4^{\circ} \mathrm{C}$ for $24 \mathrm{~h}$. Prior to staining, the cells were washed twice with PBS. The cell pellets were then stained with staining buffer (PBS containing 50 $\mu \mathrm{g} /$ $\mathrm{ml}$ propidium iodide, $10 \mu \mathrm{g} / \mathrm{ml}$ RNase A, $0.1 \%$ sodium citrate and 0.1 Triton X-100) for $30 \mathrm{~min}$ at room temperature in the dark. DNA content was analyzed by flow cytometry (Becton Deckinson, USA).

\section{Proliferation assays}

The proliferation of PBL obtained from the patients and controls was assessed using the CCK-8 assay after cells were treated with PHA, NaHS or a GSK-3 $\beta$ inhibitor (LiCl) as indicated in each study. Briefly, cells were seeded at 100,000 cells per well in 96-well plates and treated with indicated conditions for 48h, and $10 \mu \mathrm{l} \mathrm{CCK}-8$ solution was added to each well, and the cells were incubated for a further $4 \mathrm{~h}$ at $37^{\circ} \mathrm{C}$. Absorbance was assessed at $450 \mathrm{~nm}$ with a microplate reader (Bio-Tek, USA). Vehicle controls for the respective inhibitors were tested simultaneously. The mean optical density (OD) of three wells in each group was used to calculate percentage of cell proliferation as follows:

Cell proliferation $(\%)=\left(\mathrm{OD}_{\text {treatment group }}-\mathrm{OD}_{\text {blank }}\right) /\left(\mathrm{OD}_{\text {control group }}-\mathrm{OD}_{\text {blank }}\right) \times 100$

\section{Western blot analysis}

At the end of treatments, PBL were washed once with PBS, and lysed with solubilization buffer (50 mM Tris-Cl, 150mM NaCl, 0.02\% $\mathrm{NaN}_{3}, 1 \%$ Triton, X-100, 5 mM EDTA, $0.1 \mathrm{mM}$ PMSF, 1 mM NaVO, 20 $\mu \mathrm{g} / \mathrm{ml}$ aprotinin and $20 \mu \mathrm{g} / \mathrm{ml}$ leupeptin). After centrifugation, the supernatants were collected, and the protein concentration was determined by a BCA protein assay kit (Bio-Rad, Hercules, CA). Equal amount of proteins were loaded and separated by $10 \%$ SDS-PAGE. The separated proteins were transferred onto PVDF membranes. After blocking with TBST containing 5\% nonfat milk for $1 \mathrm{~h}$, each membrane was incubated with different primary antibodies, HRP-conjugated secondary antibodies, and visualized by enhanced chemiluminescence. The results were qualified by densitometry.

\section{Statistical analysis}

Statistical comparisons were performed using independent-samples t tests or one-way analysis of variance (ANOVA) by SPSS 13.0 (SPSS, USA). For all experiments, data are presented as means \pm SD. P-values less than 0.05 were considered significant.

\section{Results}

$\mathrm{H}_{2} \mathrm{~S}$ had biphasic effects on the proliferation of lymphocytes

It is reported that $\mathrm{H}_{2} \mathrm{~S}$ regulates the proliferation and apoptosis of many kinds of cells [7]. To assess the effect of exogenous $\mathrm{H}_{2} \mathrm{~S}$ on lymphocytes from SLE patients, lymphocytes 
Fig. 1. The concentrations of $\mathrm{H}_{2} \mathrm{~S}$ in the culture medium released by NaHS $(0.25-8 \mathrm{mM})$ at different time points. The concentrations of $\mathrm{H}_{2} \mathrm{~S}$ have been measured using the Amperometric $\mathrm{H}_{2} \mathrm{~S}$ sensors at the indicated time points.

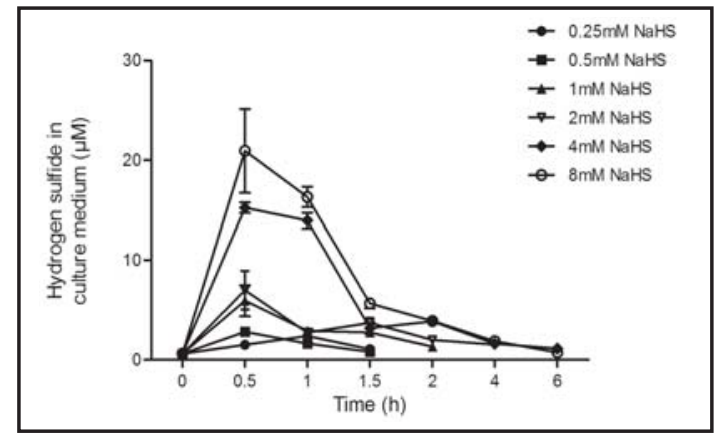

were isolated from healthy controls, SLE and RSLE patients respectively, then treated with increasing concentration of $\mathrm{NaHS}\left(\mathrm{a} \mathrm{H}_{2} \mathrm{~S}\right.$ donor, including concentrations of $0.25,0.5,1,2$, 4 and $8.0 \mathrm{mM}$ ). The concentrations of $\mathrm{H}_{2} \mathrm{~S}$ released by $0.25-8 \mathrm{mM} \mathrm{NaHS}$ at different time points were measured and shown as in Fig. 1. We observed that when treated by NaHS in low concentrations $(0.25-1 \mathrm{mM})$, the cell viability of lymphocytes from SLE and RSLE patients were increased, but decreased in higher concentrations $(\geq 2 \mathrm{mM})$, obviously at the concentration of $4 \mathrm{mM}$ (Fig. 2B, C). Cell viability of lymphocytes from healthy controls slightly increased with the treatment of NaHS in low concentration, but decreased significantly at the concentration of $2 \mathrm{mM}$ (Fig. 2A). Lymphocytes from SLE and RSLE patients proliferated obviously after treated with PHA. Pretreatment with NaHS at $4 \mathrm{mM}$ inhibited the cell viability of PHA-induced lymphocytes from SLE and RSLE patients. However, the cell viability was harmed with pretreatment of NaHS at $8 \mathrm{mM}$ (Fig. 2). Interestingly, we observed similar results in the experiment using GYY4137, which is a slow-releasing $\mathrm{H}_{2} \mathrm{~S}$ donor (Fig. 3). The results indicated that $\mathrm{H}_{2} \mathrm{~S}$ in different concentration showed different effects on proliferation of lymphocytes from both healthy controls and lupus patients. The concentration which was needed to inhibit the abnormal proliferation of lymphocytes from lupus patients was higher than that needed for the lymphocytes from healthy controls.

$\mathrm{H}_{2} \mathrm{~S}$ pretreatment changed cell cycle distribution of PHA-induced lymphocytes from SLE patients

Lymphocytes from patients and healthy controls were distributed into three cell cycle phases $\left(G_{0} / G_{1}, S\right.$ and $\left.G_{2} / M\right)$ using flow cytometry. As showed in Table 1 and Fig. 4 , after treatment with PHA for 48 hours, the percentage of lymphocytes from SLE and RSLE increased significantly in $S$ phase while decreased in $G_{0} / G_{1}$ phase compared with those from healthy controls. In addition, lymphocytes from RSLE in S phase increased more significantly than those from SLE after being stimulated with PHA. But pretreatment with NaHS (at $4 \mathrm{mM}$ ) induced lymphocytes accumulation at the $G_{0} / G_{1}$ cell cycle checkpoint. The populations in $G_{0} / G_{1}$ and $S$ phase of lymphocytes in the pretreatment with NaHS group were similar to the untreated group respectively. Additionally, we found that NaHS at $4 \mathrm{mM}$ didn't induce apoptosis of lymphocytes (Fig. 5). These observations indicated that $\mathrm{H}_{2} \mathrm{~S}$ altered the abnormal cell cycle distribution of PHA-induced lymphocytes from SLE and RSLE patients.

$\mathrm{H}_{2} \mathrm{~S}$ altered expressions of CDK2, $p 27^{K i p 1}$ and $p 21^{\text {WAF1/CIP1 }}$ in stimulated lupus lymphocytes

The interaction between CDKs and CDK inhibitors (CDKI) governs the $\mathrm{G}_{1} / \mathrm{S}$ transition. It has been proven that the upregulation of CDK2 and downregulation of $\mathrm{p} 27^{\mathrm{Kip} 1}$ and $\mathrm{p} 21^{\text {WAF1/ }}$ ${ }^{\text {CIP1 }}$ correlated with the abnormal proliferation of lymphocytes from lupus patients in our previously study[6]. Therefore we next assessed whether $\mathrm{H}_{2} \mathrm{~S}$ pretreatment would affect the expression of these proteins in lymphocytes while changing the distribution of cell cycle. As shown in Fig. 6, after treatment of lymphocytes from RSLE patients with PHA for 48 hours, the expression of CDK2 increased while the expressions of $\mathrm{p} 27^{\mathrm{Kip} 1}$ and $\mathrm{p} 21^{\mathrm{WAF} 1 / \mathrm{CIP} 1}$ decreased. However, the expressions of these three proteins in NaHS pretreatment groups (both with and without PHA treatment) showed no obvious differences to those in the untreated group 


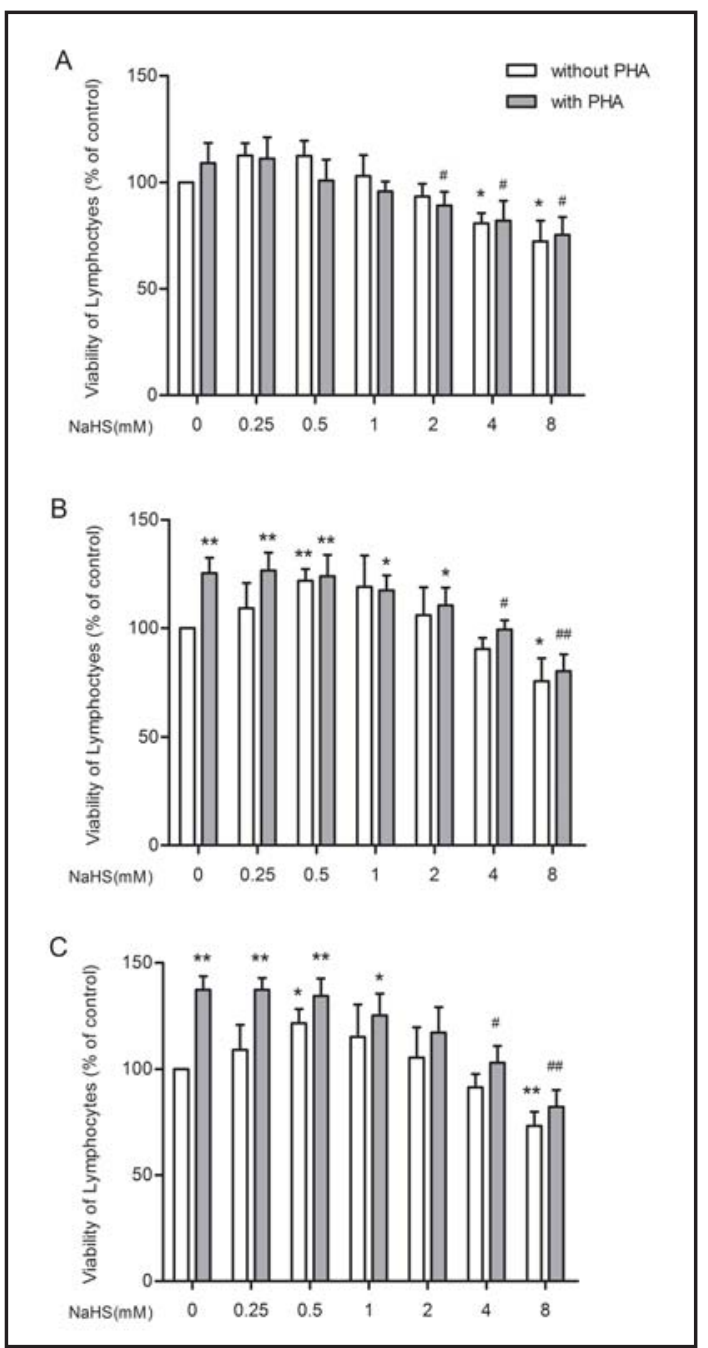

Fig. 2. Different concentration of NaHS showed different effects on lymphocytes. Lymphocytes harvested from healthy controls (A), SLE patients without renal involvement (B) and RSLE patients (C) were pretreated with different concentrations of NaHS in the absence or presence of PHA. After 48 hours, the cell viability of lymphocytes was measured by CCK-8. Results are for five independent experiments. \#: $p<0.05$, \#\#: $p<0.01$, compared with NaHS $0 \mathrm{mM}$ with PHA treatment group; *: $p<0.05$, **: $p<0.01$, compared with NaHS $0 \mathrm{mM}$ without PHA treatment group.

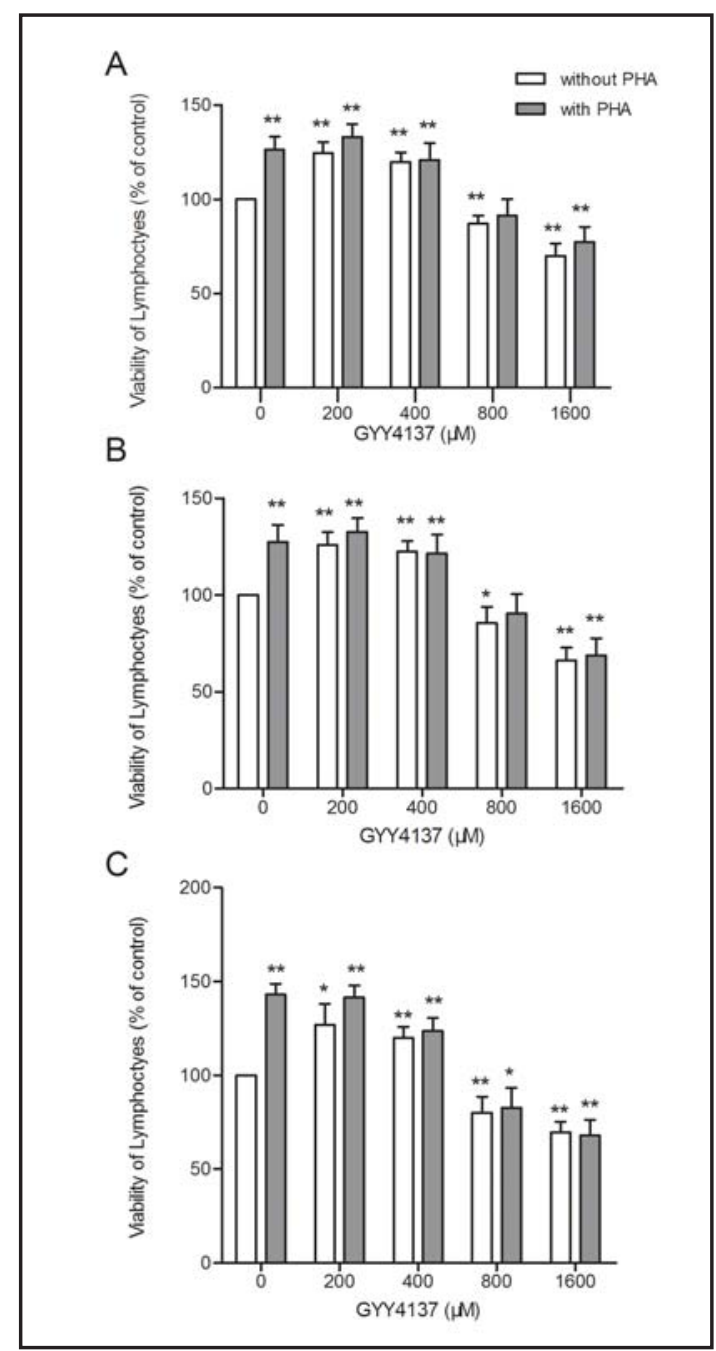

Fig. 3. Different concentration of GYY4137 showed different effects on lymphocytes. Lymphocytes harvested from healthy controls (A), SLE patients without renal involvement (B) and RSLE patients (C) were pretreated with different concentrations of GYY4137 in the absence or presence of PHA. After 48 hours, the cell viability of lymphocytes was measured by CCK-8. Results are for three independent experiments. *: $p<0.05,{ }^{* *}: p<0.01$, compared with GYY4137 $0 \mu \mathrm{M}$ without PHA treatment group.

respectively, which was in accordance with the distribution of cell cycle. The results of lymphocytes from SLE were similar to those from RSLE, but the changes were less obvious (figures not shown). These findings suggested that the inhibition of $\mathrm{H}_{2} \mathrm{~S}$ against proliferation caused by PHA was associated with the altered expressions of CDK2, p27 ${ }^{\text {Kip } 1}$ and p21 $1^{\text {WAF1/CIP1 }}$ in lymphocytes of SLE patients.

$\mathrm{H}_{2} \mathrm{~S}$ changed the phosphorylation levels of AKT and GSK3 $\beta$ in lupus lymphocytes

Phosphorylation levels of AKT and its downstream target GSK3 $\beta$ increased in stimulated lupus lymphocytes, especially in those from RSLE, as what was demonstrated in our previously 


\begin{tabular}{|c|c|c|c|c|c|c|c|c|c|}
\hline \multirow{3}{*}{$\begin{array}{l}\text { Group } \\
\text { NaHS/PHA }\end{array}$} & \multicolumn{9}{|c|}{ Cell cycle distribution (\%) } \\
\hline & \multicolumn{3}{|c|}{$\mathrm{G}_{0} / \mathrm{G}_{1}$} & \multicolumn{3}{|c|}{$S$} & \multicolumn{3}{|c|}{$\mathrm{G}_{2} / \mathrm{M}$} \\
\hline & -1 & $-1+$ & $+/+$ & -1 & $-1+$ & $+1+$ & -1 & $-1+$ & $+1+$ \\
\hline Control & $96.78 \pm 0.85$ & $86.76 \pm 1.89$ & $96.77 \pm 1.72$ & $1.81 \pm 0.67$ & $9.82 \pm 0.92$ & $1.03 \pm 0.81$ & $1.41 \pm 0.64$ & $3.42 \pm 0.66$ & $2.20 \pm 0.56$ \\
\hline SLE & $95.38 \pm 0.97$ & $77.25 \pm 2.06^{\circ}$ & $96.32 \pm 1.18$ & $2.11 \pm 0.71$ & $20.29 \pm 0.84^{*}$ & $1.82 \pm 0.94$ & $2.51 \pm 0.71$ & $2.46 \pm 0.58$ & $1.86 \pm 0.47$ \\
\hline RSLE & $94.94 \pm 1.04$ & $68.48 \pm 1.81^{* \#}$ & $97.15 \pm 1.43$ & $2.04 \pm 0.59$ & $28.61 \pm 0.89^{*}$ & $1.87 \pm 1.12$ & $3.02 \pm 0.69$ & $2.91 \pm 0.76$ & $0.98 \pm 0.52$ \\
\hline
\end{tabular}

Table 1. Distribution of cells according to cell cycle phase. ${ }^{*} p<0.05$ compared with Control with PHA treatment group, \# $p<0.05$ compared with SLE with PHA treatment group. Lymphocytes from healthy controls, SLE patients without renal involvement and RSLE patients were treated as indicated. -/-: untreated; -/+: treated with $2 \mu \mathrm{g} / \mathrm{ml}$ PHA for 48 hours; +/+: treated with $4 \mathrm{mM}$ NaHS for 30 minutes before $2 \mu \mathrm{g} / \mathrm{ml}$ PHA for 48 hours. $\mathrm{N}=5$.

Fig. 4. $\mathrm{H}_{2} \mathrm{~S}$ pretreatment changed cell cycle distribution of PHA-induced lymphocytes from SLE patients. Lymphocytes from healthy controls (A), SLE patients without renal involvement (B) and RSLE patients (C) were pretreated with or without NaHS $(4 \mathrm{mM})$ for 30 minutes in the presence or absence of PHA $(2 \mu \mathrm{g} / \mathrm{ml})$ as indicated. 48 hours after different treatments, Cells were collected and analyzed by flow cytometry. NaHS/PHA: -/-: untreated; -/+: treated with PHA $(2 \mu \mathrm{g} / \mathrm{ml})$ for 48 hours; +/+: treated with NaHS (4mM) for 30 minutes before PHA $(2 \mu \mathrm{g} / \mathrm{ml})$ for 48 hours. $\mathrm{N}=5$.

A
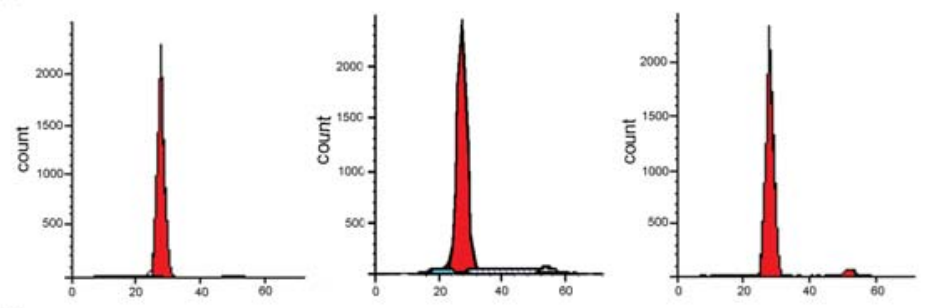

B
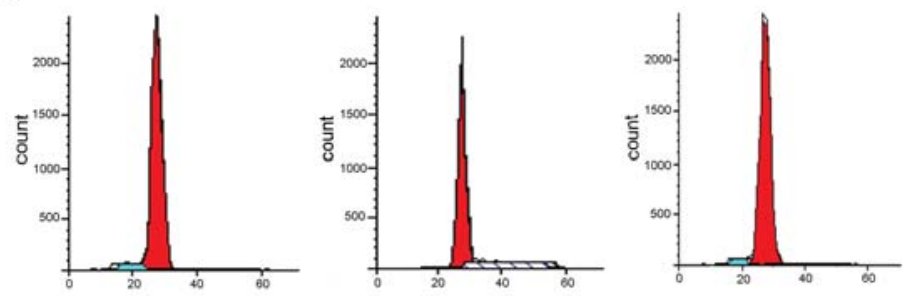

C

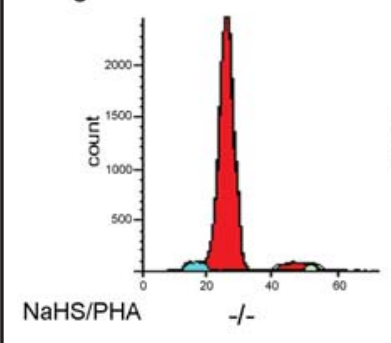

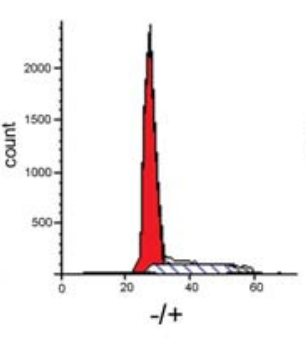

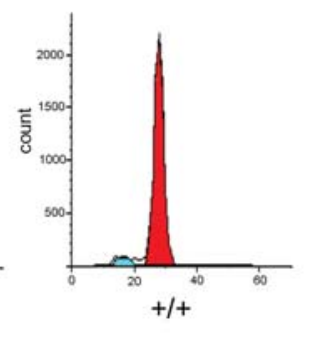

Fig. 5. The apoptosis percentages of lymphocytes from healthy controls, SLE and RSLE patients after treatment with or without NaHS at the indicated time points. Peripheral blood lymphocytes (PBL) were isolated from heparinized venous blood by FicollPaque density gradient centrifugation. PBL were seeded at 1,000,000 cells per well in 24-well plates and treated with or without NaHS (4mM). Cells were collected at the indicated time points for apoptosis analysis using flow cytometry. It showed no obvious

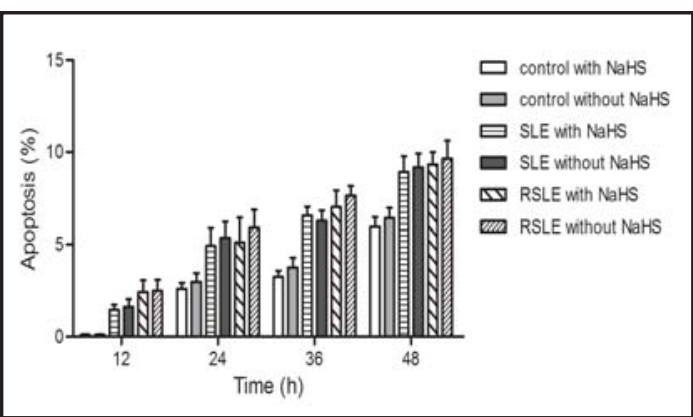
differences of apoptosis percentages of lymphocytes from healthy controls, SLE and RSLE patients between the groups treated with or without NaHS $4 \mathrm{mM}$ at 12, 24, 36 and 48 hours.

study [6]. As shown in Fig. 7A, B, C and D, the phosphorylation levels of AKT (ser473) and GSK3 $\beta$ (ser9) in lymphocytes of RSLE were increased significantly after stimulation with PHA. Pretreatment with NaHS in the absence of PHA attenuated the phosphorylation levels of AKT (ser473) but not of GSK3 $\beta$ (ser9). In the group receiving pretreatment with NaHS 
Fig. 6. Changes in the expression of cell cycle regulatory proteins in lymphocytes from RSLE. Lymphocytes separated from RSLE patients were treated with or without PHA for 48 hours in the presence or absence of NaHS (4mM) for 30 min. Cell lysates were subjected to Western blot analysis using CDK2, $\mathrm{p} 27^{\mathrm{Kip} 1}$ and $\mathrm{p} 21^{\mathrm{WAF} 1 / \mathrm{CIP} 1}$ specific antibodies. A: representative figure. $\mathrm{B}$, $\mathrm{C}, \mathrm{D}$ : The mean $\pm \mathrm{SD}$ values of 5 individual samples are plotted ${ }^{*} p<0.05$, ** $p<0.01$ compared with untreated group (NaHS/ PHA: -/-)).
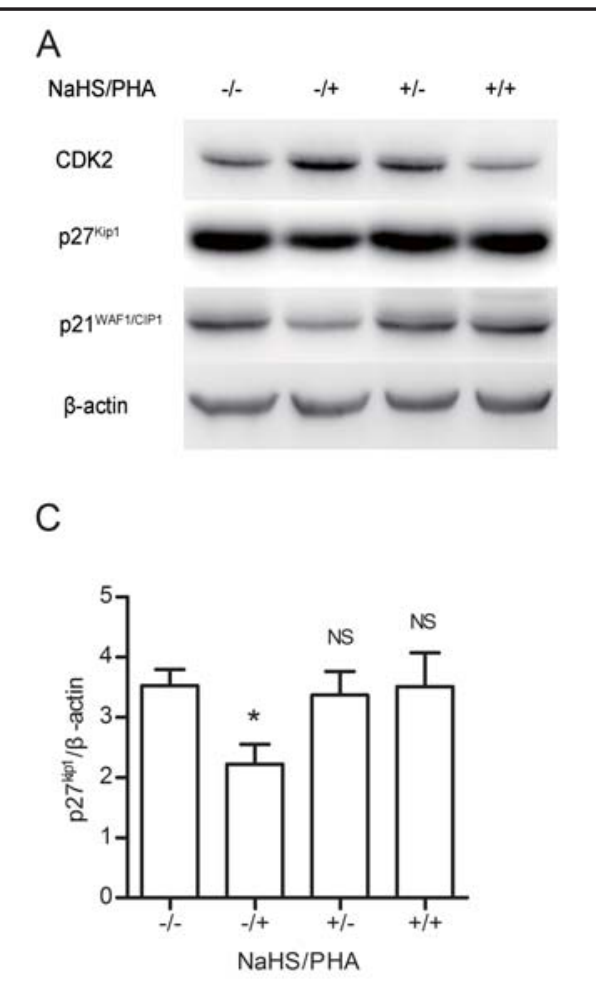

B

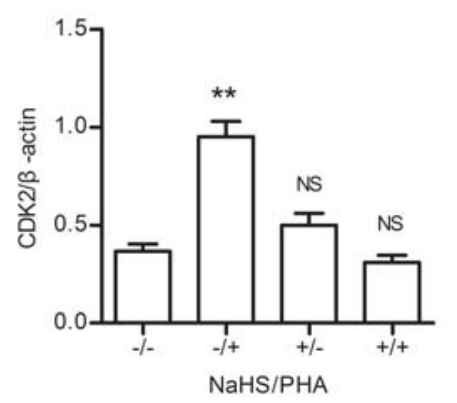

D

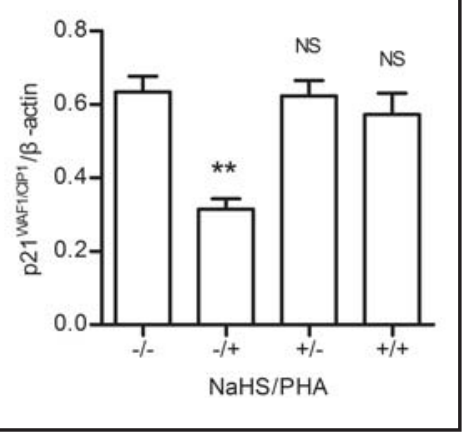

and PHA stimulation, the phosphorylation levels of AKT (ser473) and GSK3 $\beta$ (ser9) were similar to the untreated group respectively. The expression of PTEN, which is the upstream regulator of AKT, was also influenced, decreasing in the PHA-induced group but increasing in the pretreatment with NaHS groups (either with or without PHA-induced). In order to further clarify the relation between $\mathrm{H}_{2} \mathrm{~S}$ and AKT/GSK3 $\beta$ signal pathway, the lymphocytes were stimulated with GSK3 $\beta$ inhibitor lithium chloride $(\mathrm{LiCl}, 12.5 \mathrm{mM})$ for 48 hours in the absence or presence of NaHS pretreatment, and the cell viability was analyzed using CCK8 assay. The increases of lymphocytes viability were $45.9 \%$ and $55.4 \%$ for SLE and RSLE lymphocytes respectively. Pretreatment with NaHS prior to exposure of lymphocytes to $\mathrm{LiCl}$ markedly inhibited the lymphocytes viability (Fig. 7E). These results suggested that AKT/ GSK3 $\beta$ signal pathway was involved in the regulation of $\mathrm{H}_{2} \mathrm{~S}$ in the abnormal activation of lymphocytes from SLE patients.

\section{Discussion}

$\mathrm{H}_{2} \mathrm{~S}$ has been classified as a third gasotransmitter signaling molecule alongside nitric oxide (NO) and carbon monoxide (CO). Endogenous $\mathrm{H}_{2} \mathrm{~S}$ is produced by tissuespecific enzymes, including cystathionine- $\beta$-synthase (CBS), cystathionine- $\gamma$-lyase (CSE) and 3-mercaptosulfurtransferase (MST) [14]. So far, it is increasingly recognized as an important signaling molecule, regulating multiple cellular functions during normal and pathophysiological states. As a gasotransmitter, $\mathrm{H}_{2} \mathrm{~S}$, which travels through the cell membranes without specific receptors, is involved in modulating cell proliferation and apoptosis in a variety of cells $[7,15]$. NaHS is used as a common donor of $\mathrm{H}_{2} \mathrm{~S}$. The concentration of NaHS used in the previous experiments were mainly at 20-1000 $\mu \mathrm{M}$, rarely in 1-5 mM in the experiment studying rat intestinal crypt cells or human blood neutrophils [16]. Mirandola et al. showed that NaHS in $2 \mathrm{mM}$ reduced the cellular cytotoxic response of peripheral blood lymphocytes [11], while recently W. Miller et al. showed that $\mathrm{H}_{2} \mathrm{~S}$ enhanced $\mathrm{T}$ cell activation in physiological levels (50-500 $\mathrm{nM}$ ) [12]. In this study, we found that $\mathrm{H}_{2} \mathrm{~S}$ at 
Fig. 7. $\mathrm{H}_{2} \mathrm{~S}$ inhibited the abnormal proliferation of lymphocytes from RSLE through AKT/ GSK3 $\beta$ signal pathway. Lymphocytes separated from RSLE patients were treated with or without PHA for 48 hours in the presence or absence of NaHS at $4 \mathrm{mM}$ for $30 \mathrm{~min}$. Cell lysates were subjected to Western blot analysis using phosphoAKT(ser473), total AKT, phosphoPTEN specific antibodies. A: representative figure. $\mathrm{B}, \mathrm{C}, \mathrm{D}$ : The mean \pm SD values of 5 individual samples are plotted ${ }^{*} p<0.05$, ** $p<0.01$ compared with NaHS/ PHA -/- group). E: Lymphocytes separated from patients and controls were cultured for 48 hours with $\mathrm{LiCl}(12.5 \mathrm{mM})$ with or without pretreatment of NaHS at $4 \mathrm{mM}$ for $30 \mathrm{~min}$. The viability of lymphocytes was measured by CCK-8. *: $p<0.05$. GSK3 $\beta$ (ser9), total GSK3 $\beta$,

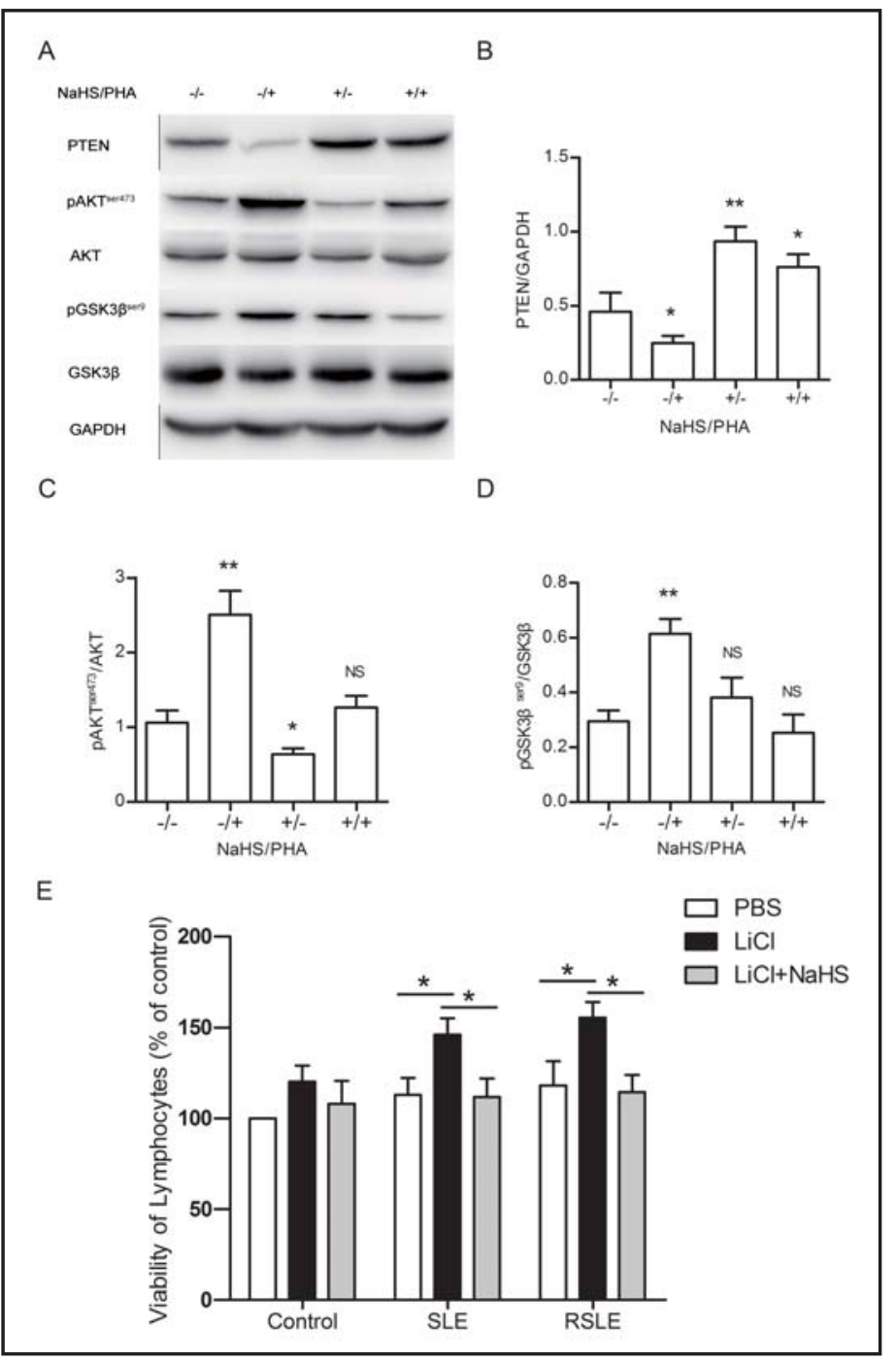

low concentrations slightly stimulated the viability of lupus lymphocytes, but inhibited the abnormal proliferation of lupus lymphocytes stimulated by PHA in higher concentration. The results were similar when using NaHS or GYY4137 as $\mathrm{H}_{2} \mathrm{~S}$ donor. The best inhibition effect achieved with pretreatment of NaHS at $4 \mathrm{mM}$ group. Such discrepancies can be due to the different protocols using in experiments according to the different aims. NaHS was used after PHA-stimulation in the study of Mirandola et al, while NaHS treated cells before PHA-stimulation, using as a pretreated protection in this study. The various sources of experimental cells may be also responsible. In the studies of Mirandola et al., the peripheral blood lymphocytes were separated from healthy volunteers, while in W. Miller et al. cells were Jurkat T cells or from mice. However, it has been proved that the PHA-stimulated lymphocytes from SLE or RSLE proliferated more obviously than that from healthy controls in the present and previous studies $[3,6]$. This is probably the reason why higher concentration of NaHS was needed to inhibit the PHA-stimulated proliferation of lymphocytes from lupus patients. Pretreatment with NaHS in $4 \mathrm{mM}$ didn't induce more apoptosis of lymphocytes from lupus patients than those from healthy controls (as shown in Fig. 5). However, the viability of lymphocytes was damaged when treated with NaHS at higher concentration in both healthy controls and lupus patients.

It has been established that $\mathrm{H}_{2} \mathrm{~S}$ acted as a cyclin dependent kinase inhibitor in cell cycle progression of the rat smooth muscle, human lung fibroblast, and oral epithelial cells and so on [7], and altered the expression of extracellular signal-regulated kinase (ERK), 


\section{Cellular Physiology and Biochemistry}

Cell Physiol Biochem 2013;31:795-804

DOI: $10.1159 / 000350097$

Publisned onine: IVIay 31, 2013

(c) 2013 S. Karger AG, Basel

www.karger.com/cpb

Han et al.: $\mathrm{H}_{2} \mathrm{~S}$ inhibits Proliferation of Lymphocytes in SLE Patients

p38 MAPK and p21 [17]. In this study, $\mathrm{H}_{2} \mathrm{~S}$ pretreatment (at the concentration of $4 \mathrm{mM}$ ) changed cell cycle distribution of PHA-stimulated lymphocytes from SLE and RSLE patients. NaHS pretreatment also modified the abnormal expressions of CDK2, p2 $7^{\text {Kip } 1}$ and p21 ${ }^{\text {WAF1/CIP1 }}$ from lupus lymphocytes inducing by PHA-stimulation. The results were in accordance of the previous studies, which indicates that treatment of $\mathrm{H}_{2} \mathrm{~S}$ alters the abnormal expression of cell cycle regulatory proteins in lymphocytes from SLE and RSLE patients, and then prevents the entering of the $\mathrm{S}$ phase.

The AKT/GSK3 $\beta$ pathway is an important signal pathway in regulating the growth, proliferation and survival of lymphocytes. PTEN (phosphatase and tensin homologue) is a phosphoinositide 3-phosphatase that converts PtdIns $(3,4,5) \mathrm{P} 3$ back into PtdIns(4,5)P2. In cells lacking PTEN, basal PtdIns(3,4,5)P3 levels are increased and receptor stimulation causes exaggerated PI3K signaling [3]. Cristofano, A. et al. established that PTEN heterozygous (PTEN+/-) mutants in mice develop a lethal polyclonal autoimmune disorder, what's more, $\mathrm{T}$ lymphocytes from these mice show reduced activation-induced cell death and increased proliferation upon activation [18]. AKT activation is mainly controlled by phosphorylation at Ser473 in human. Its downstream target, GSK3 $\beta$ activity is required to induce apoptosis of lymphocytes while its inhibitor promotes lymphocytes viability. The results of this study were consistent with these reports and our previously study [6]. $\mathrm{H}_{2} \mathrm{~S}$ in high concentration modified the abnormal activity of AKT/GSK3 $\beta$ signal pathway. Interestingly, pretreatment with $\mathrm{H}_{2} \mathrm{~S}$ alone suppressed the phosphorylation levels of AKT at ser473, but increased the expression of PTEN. It demonstrates that $\mathrm{H}_{2} \mathrm{~S}$ pretreatment induces the stable state of lupus lymphocytes through this signal pathway.

As the progression in the studies of $\mathrm{H}_{2} \mathrm{~S}$, more and more therapeutic potential of $\mathrm{H}_{2} \mathrm{~S}$ have been found. Exogenous $\mathrm{H}_{2} \mathrm{~S}$ ameliorates myocardial dysfunction associated with the ischemia/reperfusion injury, and reduces the damage of gastric mucosa induced by antiinflammatory drugs $[8,19]$. But NaHS rapidly (within seconds) generated $\mathrm{H}_{2} \mathrm{~S}$ in buffer and did not affect plasma $\mathrm{H}_{2} \mathrm{~S}$ concentration when injected intravenously in animal experiments [20]. $\mathrm{H}_{2} \mathrm{~S}$-donating drugs have been synthesized and tested in vivo and in vitro [21]. Chattopadhyay et al. showed that Hydrogen sulfide-releasing non-steroidal anti-inflammatory drugs (HSNSAIDs) inhibited proliferation, induced apoptosis, and caused $G_{0} / G_{1}$ cell cycle block of HT-29 colon cancer cell [22]. John L. et al. established that HS-NSAIDs inhibited cycloxygenase-1 and cyclooxygenase- 2 activity as effectively as NSAIDs, and reduced the prostaglandin synthesis. What's more, HS-NSAIDs did not induce leukocyte adherence whereas NSAIDs did [23]. These studies provide the clues for $\mathrm{H}_{2} \mathrm{~S}$ treatment to SLE, such as gastrointestinal protection, anti-inflammatory, vasodilatation and so on [24]. The results of this study provided evidence for therapeutic prospect of $\mathrm{H}_{2} \mathrm{~S}$ to SLE, suppressing the abnormal proliferation of lupus lymphocytes. Further studies are required, such as animal experiment in vivo and the effects of $\mathrm{H}_{2} \mathrm{~S}$ to different subsets of lymphocytes or organs from SLE and so on.

In conclusion, $\mathrm{H}_{2} \mathrm{~S}$ inhibited the abnormal activation and proliferation of lupus lymphocytes through AKT/GSK3 $\beta$ signal pathway.

\section{Acknowledgements}

This work was supported by grants from National Natural Science Foundation of China (No. 30972661) and by Science and Technology Foundation of Guangdong Province (No. 2010B031600214).

\section{References}

1 Crispín JC, Liossis S-NC, Kis-Toth K, Lieberman LA, Kyttaris VC, Juang Y-T, Tsokos GC: Pathogenesis of human systemic lupus erythematosus: Recent advances. Trends Mol Med 2010;16:47-57. 


\section{Cellular Physiology and Biochemistry}

Cell Physiol Biochem 2013;31:795-804

\begin{tabular}{l|l}
\hline DOI: $10.1159 / 000350097$ & (C) 2013 S. Karger AG, Basel
\end{tabular}

Han et al.: $\mathrm{H}_{2} \mathrm{~S}$ inhibits Proliferation of Lymphocytes in SLE Patients

2 King PD: Lupus-like autoimmunity caused by defects in t-cell signal transduction. Curr Opin Investig Drugs 2004;5:517-523.

-3 So L, Fruman DA: Pi3k signalling in b- and t-lymphocytes: New developments and therapeutic advances. Biochem J 2012;442:465-481.

4 Zhu J, Liu X, Xie C, Yan M, Yu Y, Sobel ES, Wakeland EK, Mohan C: T cell hyperactivity in lupus as a consequence of hyperstimulatory antigen-presenting cells. J Clin Invest 2005;115:1869-1878.

5 Wu T, Mohan C: The akt axis as a therapeutic target in autoimmune diseases. Endocr Metab Immune Disord Drug Targets 2009;9:145-150.

-6 Tang H, Tan G, Guo Q, Pang R, Zeng F: Abnormal activation of the akt-gsk3 $\beta$ signaling pathway in peripheral blood t cells from patients with systemic lupus erythematosus. Cell Cycle 2009;8:2789-2793.

7 Baskar R, Bian J: Hydrogen sulfide gas has cell growth regulatory role. Eur J Pharmacol 2011;656:5-9.

8 Baskar R, Sparatore A, Del Soldato P, Moore PK: Effect of s-diclofenac, a novel hydrogen sulfide releasing derivative inhibit rat vascular smooth muscle cell proliferation. Eur J Pharmacol 2008;594:1-8.

-9 Suzuki K, Olah G, Modis K, Coletta C, Kulp G, Gero D, Szoleczky P, Chang T, Zhou Z, Wu L, Wang R, Papapetropoulos A, Szabo C: Hydrogen sulfide replacement therapy protects the vascular endothelium in hyperglycemia by preserving mitochondrial function. Proc Natl Acad Sci 2011;108:13829-13834.

10 Yang C, Yang Z, Zhang M, Dong Q, Wang X, Lan A, Zeng F, Chen P, Wang C, Feng J: Hydrogen sulfide protects against chemical hypoxia-induced cytotoxicity and inflammation in hacat cells through inhibition of ros/ nf-kappab/cox-2 pathway. PLoS ONE 2011;6:e21971.

11 Mirandola P, Gobb G, Sponzilli I, Pambianco M, Malinverno C, Cacchioli A, Panfilis Gd, Vitale M: Exogenous hydrogen sulfide induces functional inhibition and cell death of cytotoxic lymphocytes subsets. J Cell Physiol 2007;213:826-833.

12 Miller TW, Wang EA, Gould S, Stein EV, Kaur S, Lim L, Amarnath S, Fowler DH, Roberts DD: Hydrogen sulfide is an endogenous potentiator of $t$ cell activation. J Biol Chem 2012;287:4211-4221.

13 Zhou K, Gao Q, Zheng S, Pan S, Li P, Suo K, Simoncini T, Wang T, Fu X: 17beta-estradiol induces vasorelaxation by stimulating endothelial hydrogen sulfide release. Mol Hum Reprod 2013;19:169-176.

14 Hughes MN, Centelles MN, Moore KP: Making and working with hydrogen sulfide: The chemistry and generation of hydrogen sulfide in vitro and its measurement in vivo: A review. Free Radic Biol Med 2009;47:1346-1353.

15 Li L, Rose P, Moore PK: Hydrogen sulfide and cell signaling. Annu Rev Pharmacol Toxicol 2011;51:169-187.

- 16 Deplancke B, Gaskins HR: Hydrogen sulfide induces serum-independent cell cycle entry in nontransformed rat intestinal epithelial cells. FASEB J 2003;17:1310-1312.

17 Rinaldi L, Gobbi G, Pambianco M, Micheloni C, Mirandola P, Vitale M: Hydrogen sulfide prevents apoptosis of human pmn via inhibition of p38 and caspase 3. Lab Invest 2006;86:391-397.

18 Di Cristofano A, Kotsi P, Peng YF, Cordon-Cardo C, Elkon KB, Pandolfi PP: Impaired fas response and autoimmunity in pten+/- mice. Science 1999;285:2122-2125.

19 Szabo C: Hydrogen sulphide and its therapeutic potential. Nat Rev Drug Discov 2007;6:917-935.

20 Ewelina Łowicka, Bełtowski J: Hydrogen sulfide (h2s)- the third gas of interest for pharmacologists. Pharmacol Rep 2007;59:4-24.

21 Olson KR: The therapeutic potential of hydrogen sulfide: Separating hype from hope. Am J Physiol Regul Integr Comp Physiol 2011;301:17.

-22 Chattopadhyay M, Kodela R, Nath N, Dastagirzada YM, Velazquez-Martinez CA, Boring D, Kashfi K: Hydrogen sulfide-releasing nsaids inhibit the growth of human cancer cells: A general property and evidence of a tissue type-independent effect. Biochem Pharmacol 2012;83:715-722.

23 Wallace JL, Caliendo G, Santagada V, Cirino G, Fiorucci S: Gastrointestinal safety and anti-inflammatory effects of a hydrogen sulfide-releasing diclofenac derivative in the rat. Gastroenterology 2007;132:261271.

-24 Zavaczki E, Jeney V, Agarwal A, Zarjou A, Oros M, Katko M, Varga Z, Balla G, Balla J: Hydrogen sulfide inhibits the calcification and osteoblastic differentiation of vascular smooth muscle cells. Kidney Int 2011;80:731739. 